\title{
Eficácia e Perda do Herbicida 2,4-D Amina Aplicado com Diferentes Volumes de Calda e Pontas de Pulverização ${ }^{1}$
}

\author{
Efficacy and Loss of 2,4-D Amine Herbicide Applied at Different Spray Volumes and \\ Nozzles
}

SOUZA, L.A. ${ }^{2}$, CUNHA, J.P.A.R. ${ }^{3}$ e PAVANIN, L.A. ${ }^{4}$

\begin{abstract}
RESUMO - O presente trabalho teve como objetivo avaliar a eficácia do herbicida 2,4-D amina na dessecação de plantas daninhas, bem como quantificar as suas perdas durante o processo de aplicação, com a utilização de diferentes volumes de calda e pontas de pulverização. $\mathrm{O}$ experimento foi conduzido em delineamento de blocos casualizados, com seis tratamentos e quatro repetições, dispostos em esquema fatorial $3 \times 2$ : três pontas de pulverização (ponta de jato plano duplo de pré-orifício, jato plano defletor e jato plano defletor com indução de ar) e dois volumes de aplicação (80 e $\left.130 \mathrm{~L} \mathrm{ha}^{-1}\right)$ com a presença do ingrediente ativo 2,4-D amina (806 g ha-1 de i.a.). Foi realizada a avaliação de deposição de calda nas plantas daninhas, perdas para o solo e perdas por exoderiva, pela quantificação do herbicida nos diferentes alvos por cromatografia liquida de alta eficiência (HPLC). Também foi avaliado o controle de plantas daninhas na área experimental. Concluiu-se que o volume de aplicação de $80 \mathrm{~L} \mathrm{ha}^{-1}$ e gotas grossas podem ser utilizados na dessecação com o herbicida 2,4-D amina, sem comprometer a cobertura do alvo; pontas de jato plano defletor com indução de ar promoveram maior perda de herbicida para o solo; e as diferentes pontas de pulverização empregadas, com gotas médias, grossas e muito grossas, bem como os volumes de aplicação de 80 e $130 \mathrm{~L} \mathrm{ha}^{-1}$, não influenciaram o controle das plantas daninhas. Não se detectou exoderiva com a metodologia empregada.
\end{abstract}

Palavras-chave: tecnologia de aplicação, planta daninha, deposição de calda, deriva.

\begin{abstract}
This study evaluated the efficacy of the herbicide 2,4-D amine in weed control, and spraying losses using different nozzles and spray volumes. The experiment was arranged in a randomized block design with six treatments and four replications, totaling 24 plots, in a $3 \times 2$ factorial model: three spray nozzles (drift guard twin flat fan, turbo flat fan and air induction turbo flat fan) and two spray volumes (80 L ha $\mathrm{L}^{-1}$ and $130 \mathrm{~L} \mathrm{ha-1)}$. The active ingredient used was 2, 4-D amine (806 $\mathrm{g} \mathrm{ha} \mathrm{h}^{-1}$ a.i.). Spray deposition on the weeds, losses to the soil and exo-drift losses were evaluated, as well as weed control in the area. Evaluations of spray deposition on the weeds, drift and losses to the soil were carried out by herbicide quantification using high-performance liquid chromatography (HPLC). According to the results obtained, it was concluded that the spray volume of $80 \mathrm{~L} \mathrm{ha-1}$ and coarse droplets can be used for weed desiccation with the herbicide 2, 4-D amine, without compromising target coverage; air induction turbo flat fan nozzles promoted greater herbicide loss to the soil; the different nozzles used, with medium, coarse, and very coarse droplets, as well as the spray volumes $80 \mathrm{~L} \mathrm{ha}^{-1}$ and $130 \mathrm{~L} \mathrm{ha}^{-1}$, did not affect weed control. Drift was not detected with the methodology applied.
\end{abstract}

Keywords: spray technology, weed, deposition, drift.

1 Recebido para publicação em 16.11.2010 e na forma revisada em 31.1.2011.

2 Engo-Agr ${ }^{0}$.,Aluno do Programa de Pós-Graduação em Agronomia, Instituto de Ciências Agrárias, Universidade Federal de Uberlândia - ICIAG/UFU, 38400-902 Uberlândia-MG, <lelioagro@terra.com.br>; ${ }^{3}$ Professor, Dr., ICIAG/UFU <jpcunha@iciag.ufu.br>; ${ }^{4}$ Professor, Dr., Instituto de Química, IQ/UFU, 38400-902 Uberlândia-MG, <pavanin@ufu.br>. 


\section{INTRODUÇÃO}

Os produtos fitossanitários, embora desempenhem papel importante no sistema de produção agrícola, têm sido alvo de crescente preocupação por parte dos diversos segmentos da sociedade, em virtude de seu potencial de risco. O 2,4-D amina é um herbicida de grande uso na agricultura, empregado no controle de plantas daninhas em pós-emergência e dessecação, porém é um dos principais produtos cuja utilização vem sendo questionada quanto ao risco ambiental. Com o uso extensivo e muitas vezes inadequado, tornou-se um problema, principalmente devido à contaminação do solo e de água subterrânea (Fu et al., 2009). Também tem ocasionado problemas em áreas vizinhas, com danos às culturas sensiveis a ele (Oliveira Júnior et al., 2007).

A deriva é o desvio da trajetória das partículas liberadas pelo processo de aplicação e que não atingem o alvo, ocasionando, portanto, perdas do produto. Essa perda dentro da cultura (material que não é coletado pelas folhas e cai no solo) pode ser considerada como endoderiva, enquanto as perdas para fora da área tratada podem ser consideradas como exoderiva.

Uma das maneiras de maximizar a eficiência da aplicação e minimizar as perdas e os riscos de contaminação provocados por defensivos agrícolas, como o 2,4-D amina, pode ser a utilização de técnicas de aplicação adequadas a cada situação, a fim de melhorar o depósito no alvo (Cunha, 2008; Rodrigues et al., 2010).

Além de estudar fatores inerentes às plantas daninhas a serem controladas, é imprescindivel também estudar fatores ligados à aplicação, como o produto a ser aplicado, o tamanho e a densidade de gotas, as perdas para o solo e por deriva, o equipamento pulverizador, o volume de calda e as pontas de pulverização. Muitos estudos de eficácia têm sido realizados, contudo sem considerar o processo como um todo, incluindo os estudos de perdas para o solo e deriva. Essas perdas para locais não alvo continuam sendo um dos maiores problemas da agricultura moderna (Tsai et al., 2005).

Autores como Cunha \& Silva Jr. (2010) consideram as pontas de pulverização partes muito importantes de uma aplicação, pois é por meio delas que são geradas as gotas (água + produto) que entrarão em contato direto com o alvo biológico. O modelo da ponta, a sua distância em relação ao alvo, a pressão, o tipo de calda utilizada e a velocidade da aplicação, além de interferirem no tamanho dessas gotas, também estão diretamente relacionados à qualidade da pulverização e da deposição das gotas, além de interferirem no potencial de deriva (Camara et al., 2008).

Atualmente, existem no mercado pontas de pulverização hidráulicas de vários tipos e usos definidos para diferentes condições operacionais. Cunha \& Pereira (2009) afirmam, no entanto, que alguns tipos ainda necessitam de informações que auxiliem no momento da escolha, como as pontas com indução de ar. Apesar de o processo de inclusão de ar nas gotas fazer com que estas aumentem de tamanho e minimizem problemas ambientais, como a deriva (Lesnik et al., 2005), algumas informações a respeito do real funcionamento dessas pontas são desconhecidas (Zhu et al., 2004; Nuyttens et al., 2007), o que limita a sua utilização.

Outra informação de grande importância para condições de campo refere-se à possibilidade de redução dos volumes de calda atualmente empregados, pois dessa forma seria possivel aumentar a capacidade operacional e a autonomia dos pulverizadores. Isso reduziria o custo da aplicação, porém requer o estudo sobre o não comprometimento da eficiência do processo de aplicação.

Nesse sentido, Souza et al. (2007) comentam sobre a dificuldade de avaliar depósitos em plantas infestantes, em virtude da desuniformidade de um processo de pulverização realizado em condições de campo. Métodos que permitem a quantificação direta do ingrediente ativo - como, por exemplo, através da cromatografia - apresentam a vantagem de serem menos sujeitos a erros do que as metodologias que empregam traçadores.

O objetivo deste trabalho foi avaliar a dessecação de plantas daninhas, a deposição de calda de pulverização no alvo, as perdas para o solo e a deriva promovidos pela aplicação do herbicida 2,4-D amina, com a utilização de diferentes volumes de calda e pontas de pulverização. 


\section{MATERIAL E MÉTODOS}

Com intuito de avaliar o processo de aplicação de herbicida em dessecação de plantas daninhas, foi utilizado o ingrediente ativo 2,4-D amina (produto comercial DMA $806 \mathrm{BR}^{\circledR}$, na concentração de $806 \mathrm{~g} \mathrm{~L}^{-1}$ de i.a.) na dose de $1 \mathrm{~L} \mathrm{ha}^{-1}$ de produto comercial, conforme recomendação do fabricante, tendo como referencial teórico a instalação futura da cultura do milho. Trata-se de um herbicida recomendado para o uso em dessecação; a área utilizada para a aplicação estava em pousio há quatro meses, sendo o milho a cultura anterior.

O experimento foi conduzido no delineamento de blocos ao acaso, com seis tratamentos e quatro repetições, totalizando 24 parcelas, com área de $35 \mathrm{~m}^{2}(7 \times 5 \mathrm{~m})$, dispostos em esquema fatorial $3 \times 2$, em que os fatores foram representados por três pontas de pulverização e dois volumes de calda, conforme descrito na Tabela 1.

$\mathrm{Na}$ aplicação dos tratamentos foi utilizado um pulverizador de barra hidráulico acoplado a um trator, modelo Jacto AM-14, com barra de $14 \mathrm{~m}$, espaçamento entre bicos de $0,50 \mathrm{~m}$ e capacidade do tanque de $600 \mathrm{~L}$. A pressão de líquido empregada foi de $207 \mathrm{kPa}$, e a velocidade de deslocamento, para os volumes de aplicação de 80 e $130 \mathrm{~L} \mathrm{ha}^{-1}$, foi de 10 e $6 \mathrm{~km} \mathrm{~h}^{-1}$, respectivamente.

Para avaliar a aplicação do herbicida 2,4-D amina, foi realizado um estudo de deposição da calda nas plantas daninhas, perdas para o solo e perdas por exoderiva. Também foi realizada a avaliação da eficácia de controle das plantas daninhas presentes na área experimental. O estudo de deposição, perdas para o solo e deriva foi realizado quantificando-se o herbicida depositado sobre os alvos por cromatografia líquida de alta eficiência (HPLC - High Performance Liquid Chromatography).

Após a aplicação do herbicida, a avaliação da deposição foi realizada com a retirada das plantas daninhas de cada parcela. As plantas foram coletadas tendo como referência um quadrado de madeira medindo $0,20 \times 0,20 \mathrm{~m}$, lançado ao acaso duas vezes em cada parcela. Elas foram cortadas rente ao solo e acondicionadas em sacos plásticos. Posteriormente, as amostras foram levadas ao laboratório, para extração e determinação da quantidade de ingrediente ativo depositado. Inicialmente, as amostras foram homogeneizadas manualmente, visando não concentrar uma única espécie, sendo retirados $5 \mathrm{~g}$ de massa fresca para maceração, em presença de um volume de $25 \mathrm{~mL}$ de álcool metílico P.A. A amostra resultante foi, então, filtrada em papel-filtro e armazenada a $2{ }^{\circ} \mathrm{C}$, para posterior quantificação. Esta foi realizada em um HPLC com detector de UV-Vis, da marca Shimadzu. As condições do método cromatográfico para as análises foram: a fase móvel utilizada foi acetonitrila/água $+0,1 \% \mathrm{H}_{3} \mathrm{PO}_{4}$ na proporção de $50 / 50 \mathrm{v} / \mathrm{v}$, com fluxo de $1,4 \mathrm{~mL} \mathrm{~min}^{-1}$, forno a $30{ }^{\circ} \mathrm{C}$, detecção na região do UV-Vis, no comprimento de onda de $201 \mathrm{~nm}$ e coluna $\mathrm{C}_{18}$ com $15 \mathrm{~cm}$ de comprimento. Nessas condições, o herbicida apresentou tempo de retenção de quatro minutos.

A curva-padrão para determinação da concentração de 2,4-D amina com a técnica da cromatografia líquida nas amostras foi

Tabela 1 - Descrição dos tratamentos avaliados

\begin{tabular}{|c|l|c|c|c|}
\hline \multirow{2}{*}{ Tratamento } & \multicolumn{1}{|c|}{ Ponta de pulverização } & $\begin{array}{c}\text { Volume de } \\
\text { calda } \\
\left(\mathrm{L} \mathrm{ha}^{-1}\right)\end{array}$ & $\begin{array}{c}\text { Classificação do } \\
\text { tamanho de gota }\end{array}$ & $\begin{array}{c}\text { Diâmetro de } \\
\text { gotas - DMV } \\
(\mu \mathrm{m})\end{array}$ \\
\hline 1 & Jato plano duplo de pré-orifício - DGTJ60 11002 & 80 & Média & 216 \\
\hline 2 & Jato plano duplo de pré-orifício - DGTJ60 11002 & 130 & Média & 216 \\
\hline 3 & Jato plano defletor - TT 11002 & 80 & Grossa & 380 \\
\hline 4 & Jato plano defletor - TT 11002 & 130 & Grossa & 380 \\
\hline 5 & Jato plano defletor com indução de ar - TTI 11002 & 80 & Extremamente grossa & 925 \\
\hline 6 & Jato plano defletor com indução de ar - TTI 11002 & 130 & Extremamente grossa & 925 \\
\hline
\end{tabular}

Classificação do tamanho de gota e diâmetro da mediana volumétrica (DMV), segundo o fabricante, a $200 \mathrm{kPa}$ de pressão. 
confeccionada no intervalo de concentração de $0,10 \mathrm{mg} \mathrm{L}^{-1}$ a $2,50 \mathrm{mg} \mathrm{L}^{-1}$, em função da área apresentada no cromatograma. O coeficiente de correlação da curva foi de 0,99 , e obteve-se um limite de quantificação de $0,10 \mathrm{mg} \mathrm{L}^{-1}$ e um limite de detecção de $0,047 \mathrm{mg} \mathrm{L}^{-1}$.

A determinação do ingrediente ativo perdido para o solo foi realizada por meio da distribuição ao acaso de quatro lâminas de vidro $\left(37,24 \mathrm{~cm}^{2}\right)$ por parcela. Após a aplicação e secagem das lâminas, elas foram retiradas e armazenadas em sacos plásticos e levadas para o laboratório, onde foram lavadas com volume de 25 mL de álcool metílico P.A., para extração e quantificação do produto presente, de forma semelhante à realizada para as plantas daninhas.

Para a determinação da deriva, foram colocados a $5 \mathrm{~m}$ de distância, paralela e externamente às parcelas, no sentido de deslocamento do vento, fios de náilon de $2 \mathrm{~mm}$ de diâmetro (ISO, 2005) e com comprimento de $4 \mathrm{~m}$, a $2 \mathrm{~m}$ de altura do solo. Após a aplicação, os fios foram recolhidos, acondicionados em sacos plásticos e levados ao laboratório, para determinação do ingrediente ativo. Eles foram lavados com volume de $25 \mathrm{~mL}$ de álcool metílico P.A., para extração e posterior quantificação do produto presente, conforme metodologia descrita.

Para o depósito nas plantas daninhas, procedeu-se, então, à divisão do depósito total pela massa da amostra de remoção, obtendose a quantidade em $\mathrm{mg} \mathrm{kg}^{-1}$. Para os dados da perda para o solo e deriva, procedeu-se à divisão do depósito total pela área dos alvos, obtendo-se a quantidade em $\mu \mathrm{g} \mathrm{cm}^{-2}$.

As principais plantas daninhas da área experimental foram: Acanthospermum hispidum (carrapicho-de-carneiro), Ageratum conyzoides (mentrasto), Amaranthus deflexus (caruru), Commelina benghalensis (trapoeraba), Raphanus raphanistrum (nabiça) e Chamaesyce hirta (erva-de-santa-luzia).

$\mathrm{Na}$ análise da eficácia de controle das plantas daninhas, foram realizadas duas avaliações visuais de controle, aos 10 e aos 20 dias após a aplicação do herbicida (DAA), mediante a escala percentual de notas de controle de plantas daninhas (ALAM, 1974).
A aplicação foi realizada quando as plantas infestantes encontravam-se em estádio de pós-emergência tardia. As condições atmosféricas no momento da aplicação foram monitoradas por meio de um termo-higroanemômetro digital, onde foram registrados temperatura do ar entre 25 e $27^{\circ} \mathrm{C}$, umidade relativa entre 68 e $72 \%$ e velocidade do vento entre 8 e $10 \mathrm{~km} \mathrm{~h}^{1}$.

$\mathrm{Na}$ análise dos dados, inicialmente foram aplicados os testes de Lilliefors e Bartlett, para verificar a normalidade dos erros e a homogeneidade das variâncias. Em seguida, os dados de deposição, perdas para o solo e eficácia foram submetidos à análise de variância; quando pertinente, as médias foram comparadas pelo teste de Tukey a 0,05 de probabilidade.

\section{RESULTADOS E DISCUSSÃO}

Os dados de deposição de 2,4-D amina nas plantas daninhas estão apresentados na Tabela 2. Observa-se que a interação entre pontas e volumes não foi significativa, indicando a independência dos fatores; contudo, o efeito de pontas e volumes foi significativo. $\mathrm{O}$ volume de $80 \mathrm{~L} \mathrm{ha}^{-1}$ proporcionou maior deposição nas plantas quando comparado ao de $130 \mathrm{~L} \mathrm{ha}^{-1}$.

Tomazela et al. (2006), utilizando a ponta de jato plano XR 8001, também verificaram que a redução do volume da calda promoveu incrementos significativos na porcentagem de depósitos em Brachiaria plantaginea. Entretanto, Rodrigues et al. (2010), comparando os volume de 100 e $200 \mathrm{~L} \mathrm{ha}^{-1}$, encontraram maiores depósitos do traçador Azul Brilhante em plantas de Commelina benghalensis com o maior volume. Uma possivel explicação para essa diferença pode estar associada aos distintos padrões de cera sobre a epiderme, pois eles determinam os diferentes graus de molhabilidade da superficie foliar.

A redução do volume de aplicação, aliada à utilização de ponta com característica de gotas média e grossa, não comprometeu a eficiência e a cobertura do alvo. A uniformidade na deposição é fator importante no desempenho dos produtos fitossanitários, principalmente quando se consideram produtos de ação de contato, que exigem maior área de cobertura do alvo. 
As pontas avaliadas promoveram diferenças na deposição. A ponta de jato plano duplo de pré-orifício, com tamanho de gotas médio, gerou maior deposição nas plantas daninhas, quando comparada com a de jato plano defletor com indução de ar, com gotas extremamente grossas, porém não se diferenciou da ponta de jato plano defletor, de gotas grossas. Os resultados sugerem que as gotas médias foram mais adequadas no que se refere à deposição no alvo; contudo, o fato de se ter trabalhado com uma ponta de jato plano duplo, com gotas médias, também pode ter colaborado para esse resultado. De qualquer forma, a magnitude de variação entre as pontas $\left(2,60 \mathrm{mg}\right.$ de $\left.2,4-\mathrm{D} \mathrm{kg}{ }^{-1}\right)$ não foi grande. Cunha et al. (2008) afirmam que as pontas de jato plano duplo apresentam maior capacidade de penetração no dossel das plantas, em comparação às de jato plano simples.
Na Tabela 3, observa-se a massa de 2,4-D amina retida nas placas junto ao solo. A interação entre pontas e volume de aplicação foi significativa, indicando a dependência entre os fatores. Balan et al. (2006), avaliando depósito e perdas em sistema de pulverização com turboatomizador em videira, também observaram que há relação entre o tamanho de gota e o volume de calda, quando se avaliam perdas.

O volume de $130 \mathrm{~L} \mathrm{ha}^{-1}$ proporcionou maiores perdas para o solo em todas as pontas, quando comparado ao de $80 \mathrm{~L} \mathrm{ha}^{-1}$. Com este volume, a ponta de jato plano duplo com pré-orifício levou à menor perda, e a de jato plano defletor com indução de ar, à maior. As gotas muito grossas têm maior peso e, por isso, maior dificuldade de retenção na folhagem, tendo como destino final, muitas vezes, o solo. Para o volume de $130 \mathrm{~L} \mathrm{ha}^{-1}$, a ponta de jato

Tabela 2 - Massa de 2,4-D amina retida na folhagem das plantas daninhas (mg de 2,4-D kg-1 de matéria úmida), após a aplicação do herbicida com diferentes pontas de pulverização, em dois volumes de aplicação

\begin{tabular}{|c|c|c|c|}
\hline \multirow{2}{*}{ Ponta } & \multicolumn{2}{|c|}{ Volume de aplicação $\left(\mathrm{L} \mathrm{ha}^{-1}\right)$} & \multirow{2}{*}{ Média } \\
\hline & 80 & 130 & \\
\hline Jato plano duplo de pré-orifício & 45,08 & 42,39 & $43,73 \mathrm{a}$ \\
\hline Jato plano defletor & 44,87 & 41,05 & $42,96 \mathrm{ab}$ \\
\hline Jato plano defletor com indução de ar & 44,63 & 37,62 & $41,13 \mathrm{~b}$ \\
\hline Média & $44,86 \mathrm{~A}$ & $40,35 \mathrm{~B}$ & \\
\hline \multicolumn{4}{|c|}{ CV $(\%): 4,37$} \\
\hline Valor $\mathrm{F}$ (ponta $\mathrm{x}$ volume): $2,89^{\mathrm{ns}}$ & Valor F & Valor F & \\
\hline
\end{tabular}

ns Não significativo. ${ }^{* *}$ Significativo a 0,01 de probabilidade. ${ }^{*}$ Significativo a 0,05 de probabilidade. Médias seguidas por letras distintas, minúsculas na coluna e maiúsculas na linha, diferem entre si pelo teste de Tukey a 0,05 de probabilidade.

Tabela 3 - Massa de 2,4-D amina retida na placa junto ao solo ( $\mu \mathrm{g}$ de 2,4-D cm ch $^{-2}$, após a aplicação do herbicida com diferentes pontas de pulverização, em dois volumes de aplicação

\begin{tabular}{|c|c|c|c|}
\hline \multirow{2}{*}{ Ponta } & \multicolumn{2}{|c|}{ Volume de aplicação $\left(\mathrm{L} \mathrm{ha}^{-1}\right)$} & \multirow{2}{*}{ Média } \\
\hline & 80 & 130 & \\
\hline Jato plano duplo de pré-orifício & $0,99 \mathrm{cB}$ & $1,05 \mathrm{bA}$ & 1,02 \\
\hline Jato plano defletor & $1,16 \mathrm{bB}$ & $1,36 \mathrm{aA}$ & 1,26 \\
\hline Jato plano defletor com indução de ar & $1,22 \mathrm{aB}$ & $1,41 \mathrm{aA}$ & 1,32 \\
\hline Média & 1,12 & 1,27 & \\
\hline \multicolumn{4}{|c|}{ CV $(\%): 2,57$} \\
\hline \multicolumn{4}{|c|}{ Valor F (ponta $\mathrm{x}$ volume): $12,31^{* *}$} \\
\hline
\end{tabular}

** Significativo a 0,01 de probabilidade. Médias seguidas por letras distintas, minúsculas nas colunas e maiúsculas nas linhas, diferem entre si pelo teste de Tukey a 0,05 de probabilidade. 
plano defletor com indução de ar também ocasionou maior perda, porém não se diferenciou da ponta de jato plano defletor.

Nos últimos anos, o uso de pontas com indução de ar tem aumentado devido ao potencial de redução de deriva. No entanto, em alvos com pequena área foliar, elas podem comprometer a cobertura das plantas e promover maior potencial de escorrimento e perdas para o solo, em razão de as gotas serem de maior tamanho. $\mathrm{O}$ fato de as gotas serem formadas com ar em seu interior minimiza esse problema, mas o processo de contato e espalhamento delas com o alvo ainda não é bem conhecido (Zhu et al., 2004).

Em geral, gotas muito pequenas aumentam o risco de perdas, sobretudo por evaporação e deriva, enquanto gotas grandes podem escorrer sobre o alvo, não havendo tempo para o produto ser absorvido. Gotas pequenas e grandes possuem diferentes características para cada situação de pulverização. Gotas pequenas são recomendadas quando é necessário boa cobertura e penetração no dossel das plantas. As gotas medianas ou grandes são melhores para aplicação em condições de maior risco de deriva. Em ambos os casos, quanto mais uniforme for o tamanho das gotas produzidas pela pulverização, mais adequada será a aplicação.

A metodologia utilizada neste ensaio não proporcionou a detecção de deriva. Vale destacar que a cromatografia é atualmente o método mais sensivel para análise de resíduos de produtos fitossanitários, o que indica a pequena magnitude do fenômeno nas aplicações realizadas. Apesar de a deriva ainda ser considerada um dos maiores problemas da agricultura, nota-se que ela pode ser minimizada. Possivelmente, isso ocorreu em razão de a aplicação ter sido feita em condições adequadas de vento e em virtude do uso de gotas médias, grossas e muito grossas.

Analisando o percentual de controle das plantas daninhas, aos 10 DAA (Tabela 4), observa-se que não houve diferença entre os tratamentos. O controle das plantas daninhas promovido pelo herbicida 2,4-D classificou-se como suficiente, pela escala proposta pela ALAM. As plantas apresentavam sintomas de epinastia das folhas, crescimento anormal de ramos e curvamento do caule e das folhas para baixo, diminuindo a superficie de absorção de luz.

Resultados contraditórios quanto à eficácia de herbicidas, em relação ao volume de aplicação, foram relatados por alguns pesquisadores. Trabalhos realizados com 100 e $200 \mathrm{~L} \mathrm{ha}^{-1}$ de calda para os herbicidas lactofen e fomesafen não apresentaram diferenças no controle de plantas daninhas na cultura da soja (Ferreira et al., 1998). Galon et al. (2007) afirmam que a variação do volume de calda (100 e $200 \mathrm{~L} \mathrm{ha}^{-1}$ ), de forma geral, não exerceu interferência na eficácia dos tratamentos herbicidas no controle de Amaranthus lividus e Portulaca oleracea, empregando chlorimuronethyl, chloransulam-methyl, fomesafen, imazethapyr, lactofen e chlorimuron-ethyl + lactofen. No entanto, Roman et al. (2004) obtiveram controle mais eficiente de Brachiaria plantaginea utilizando volumes de calda menores (100 L ha ${ }^{-1}$ ).

Galon et al. (2007) afirmam que a eficácia de controle das plantas daninhas, por herbicidas sistêmicos ou de contato, pode aumentar ou diminuir com a variação do volume de calda aplicado, demonstrando que a sensibilidade das infestantes aos herbicidas pode variar em função de fatores intrínsecos à espécie e do ambiente.

O percentual de controle das plantas daninhas, avaliado aos 20 DAA (Tabela 5), foi satisfatório, com valores entre 87,50 e $92,50 \%$, não havendo diferença entre os fatores estudados.

Independentemente da ponta e do volume de aplicação, pode-se considerar que a utilização do herbicida 2,4-D amina proporcionou ótimo controle das plantas daninhas dicotiledôneas presentes na área experimental. A utilização de volumes de aplicação abaixo dos geralmente utilizados não comprometeu a eficiência de controle. O emprego de pontas de pulverização novas, com correta tecnologia de pulverização, e as boas condições climáticas no momento da aplicação contribuíram para o elevado percentual de controle das infestantes. Kruger et al. (2008) também mencionam que o 2,4-D é um produto efetivo no controle de plantas infestantes e uma opção muito econômica, principalmente para evitar problemas de resistência a glyphosate. 
Tabela 4 - Percentual de controle das plantas daninhas, avaliado aos 10 dias após a aplicação do herbicida, com diferentes pontas de pulverização, em dois volumes de aplicação

\begin{tabular}{|l|c|c|c|}
\hline \multirow{2}{*}{ Ponta } & \multicolumn{2}{|c|}{ Volume de aplicação (L ha $\left.{ }^{-1}\right)$} & \multirow{2}{*}{ Média } \\
\cline { 2 - 4 } & 80 & 130 & 69,37 \\
\hline Jato plano duplo de pré-orifício & 68,75 & 70,00 & 69,37 \\
\hline Jato plano defletor & 67,50 & 71,25 & 70,00 \\
\hline Jato plano defletor com indução de ar & 70,00 & 70,00 & 70,42 \\
\hline Média & 68,75 & \\
\hline \multicolumn{2}{|c|}{ Valor F (ponta x volume): $0,37^{\mathrm{ns}}$ Valor F (ponta): $0,05^{\mathrm{ns}}$ Valor F (volume): $0,85^{\text {ns }}$} \\
\hline
\end{tabular}

${ }^{\text {ns }}$ Não significativo a 0,05 de probabilidade.

Tabela 5 - Percentual de controle das plantas daninhas, avaliado aos 20 dias após a aplicação do herbicida, com diferentes pontas de pulverização, em dois volumes de aplicação

\begin{tabular}{|l|c|c|c|}
\hline \multirow{2}{*}{ Ponta } & \multicolumn{2}{|c|}{ Volume de aplicação $\left(\mathrm{L} \mathrm{ha}^{-1}\right)$} & \multirow{2}{*}{ Média } \\
\cline { 2 - 4 } & 80 & 130 & 90,62 \\
\hline Jato plano duplo de pré-orifício & 92,50 & 88,75 & 90,00 \\
\hline Jato plano defletor & 92,50 & 87,50 & 89,37 \\
\hline Jato plano defletor com indução de ar & 91,25 & 87,50 & 87,92 \\
\hline Média & 92,08 & \\
\hline & CV $(\%): 6,28$ & \\
\hline \multicolumn{2}{|c|}{ Valor F (ponta x volume): $0,03^{\text {ns }}$ Valor F (ponta): $0,09^{\text {ns }}$ Valor F (volume): $3,26^{\text {ns }}$} \\
\hline
\end{tabular}

ns Não significativo a 0,05 de probabilidade.

Os principais sintomas observados nas plantas de Raphanus raphanistrum, Commelina benghalensis e Amaranthus deflexus foram enrolamento das bordas apicais, murchamento e clorose foliar.

Para Furness \& Pinczewski (1985), a comparação do desempenho de sistemas de pulverização deve ser finalizada pela avaliação da eficiência biológica. Contudo, variações nas condições operacionais dos equipamentos podem não ser suficientes para resultar em diferenças significativas no controle, pelo fato de o ingrediente ativo estar em quantidade superior à necessidade em formulações comerciais (Raetano \& Matuo, 1999).

Concluiu-se que o volume de aplicação de $80 \mathrm{~L} \mathrm{ha}^{-1}$ e gotas grossas podem ser utilizados na dessecação de plantas daninhas com o herbicida 2,4-D, sem comprometer a cobertura do alvo. Observou-se maior perda de herbicida para o solo quando se utilizaram as pontas de jato plano defletor com indução de ar, entretanto, as diferentes pontas de pulverização empregadas, com gotas médias, grossas e muito grossas, bem como os volumes de aplicação de 80 e $130 \mathrm{~L} \mathrm{ha}^{-1}$, não influenciaram o controle das plantas daninhas. Não foi possivel detectar perdas por exoderiva com a metodologia empregada.

\section{AGRADECIMENTOS}

Ao CNPq, à Fapemig e à Syngenta, pelo suporte financeiro parcial, que permitiu o desenvolvimento deste trabalho de pesquisa.

\section{LITERATURA CITADA}

ASOCIACIÓN LATINO AMERICANA DE MALEZAS ALAM. Recomendaciones sobre unificación de los sistemas de evaluación en ensayos de controle de malezas. Alam, v. 1, n. 1, p. $35-38,1974$

BALAN, M. G. et al. Depósito e perdas em sistema de pulverização com turboatomizador em videira. Eng. Agríc., v. 26, n. 2 , p. $470-477,2006$ 
CAMARA, F. T. et al. Distribuição volumétrica e espectro de gotas de bicos hidráulicos de jato plano de faixa expandida XR 110 03. Eng. Agríc., v. 28, n. 4, p. 740-749, 2008.

CUNHA, J. P. A. R. et al. Efeito de pontas de pulverização no controle químico da ferrugem da soja. Eng. Agríc., v. 28, n. 2, p. 283-291, 2008.

CUNHA, J. P. A. R. Simulação de deriva de agrotóxicos em diferentes condições de pulverização. Ci. Agrotecnol., v. 32, n. 5, p. 1616-1621, 2008

CUNHA, J. P. A. R.; PEREIRA, R. G. Efeito de pontas e volumes de pulverização no controle químico de doenças do milho. Ci. Agron., v. 40, n.4, p. 533-538, 2009.

CUNHA, J. P. A. R.; SILVA Jr., A. D. Volumes de calda e pontas de pulverização no controle químico de Spodoptera frugiperda na cultura do sorgo forrageiro. Eng. Agríc., v. 30, n. 4, p. 692-699, 2010.

FERREIRA, M. C. et al. Redução da dose e do volume de calda nas aplicações noturnas de herbicidas em pósemergência na cultura da soja. Planta Daninha, v. 16, n. 1, p. 25-36, 1998.

FU, F. et al. Study on the degradation of 2,4dichlorophenoxyacetic acid (2,4-D) and 2-methyl-4-chlorophenoxyacetic sodium (MCPA sodium) in natural agriculturesoils of Fuzhou, China using capillary electrophoresis. Sci.

Total Environ., v. 6, n. 407, p. 1998-2003, 2009.

FURNESS, G. O.; PINCZEWSKI, W. V. A comparison of the spray distribution obtained from sprayers with converging and diverging airjets with low volume air assisted spraying on citrus and grapevines. J. Agric. Eng. Res., v. 32, n. 4, p. 291-310, 1985

GALON, L. et al. Controle de plantas daninhas e seletividade de herbicidas à cultura da soja, aplicados em dois volumes de calda. R. Bras. Agroci., v. 13, n. 3, p. 325-330, 2007.

ISO. ISO/FDIS 22866: Equipment for crop protection Methods for field measurement of spray drift. Geneva: 2005. $22 \mathrm{p}$
KRUGER, G. R. et al. Response and survival of rosette-stage horseweed (Conyza canadensis) after exposure to 2,4-D Weed Sci., v. 56, n. 5, p. 748-752, 2008.

LESNIK, M. et al. Comparison of the effectiveness of standard and drift-reducing nozzles for control of some pests of apple. Crop Protec., v. 24, n. 2, p. 93-100, 2005.

NUYTTENS, D. et al. Effect of nozzle type, size and pressure on spray droplet characteristics. Biosyst. Eng., v. 97, n. 3 , p. $333-345,2007$

OLIVEIRA JÚNIOR, R. S. et al. Efeito de subdoses de 2,4-D na produtividade de uva Itália e suscetibilidade da cultura em função de seu estádio de desenvolvimento. Eng. Agríc., v. 27, n. 1, p. 35-40, 2007.

RAETANO, C. G.; MATUO, T. Efeito da pulverização com turboatomizadores em diferentes condições operacionais no controle de ácaros em citros. An. Soc. Entomol. Brasil, v. 28, n. 1, p. 131-140, 1999.

RODRIGUES, A. C. P. et al. Avaliação qualitativa e quantitativa na deposição de calda de pulverização em Commelina benghalensis. Planta Daninha, v. 28, n. 2, p. 421-428, 2010.

ROMAN, E. S. et al. Influência do orvalho e volume de calda de aplicação na eficácia do glyphosate na dessecação de Brachiaria plantaginea. Planta Daninha, v. 22, n. 3, p. 479-482, 2004.

SOUZA, R. T. et al. Aspectos metodológicos para análise de depósitos de pulverizações pela determinação dos depósitos pontuais. Planta Daninha, v. 25, n. 1, p. 195-202, 2007.

TOMAZELA, M. S. et al. Avaliação da deposição da calda de pulverização em função da densidade populacional de Brachiaria plantaginea, do volume e do ângulo de aplicação. Planta Daninha, v. 24, n. 1, p. 183-189, 2006.

TSAI, M. et al. The Washington aerial spray drift study: modeling pesticide spray drift deposition from an aerial application. Atmosph. Environ., v. 39, n. 33, p. 6194-6203, 2005.

ZHU, H. et al. Spray penetration into peanut canopies with hydraulic nozzle tips. Biosyst. Eng., v. 87, n. 3, p. 275-283, 2004. 